\title{
Validation of Envisat Rain Detection and Rain Rate Estimates by Comparing With TRMM Data
}

\author{
Ngan Tran, Jean Tournadre, and Pierre Féménias
}

\begin{abstract}
This letter provides validation results on both Envisat altimeter rain detection flag and rain rate estimates. This assessment was performed based on 18-month collocated data sets between Envisat with two sensor measurements from the Tropical Rainfall Measuring Mission, i.e., the microwave imager and the precipitation radar. Along with the comparison between closest sensor measurements with strict spatial and temporal criteria, discussion is also provided on environmental context insight when interpreting comparison results based on collocated data.
\end{abstract}

Index Terms-Altimetry, radar cross sections, rain, remote sensing.

\section{INTRODUCTION}

$\mathbf{T}$ HE DETECTION of rain using dual-frequency altimeter data is well established [1], [2] and useful both for maintaining the quality of the sea surface height measurements and for studies of oceanic precipitations [3]. Indeed, rain can strongly distort the waveform echoes and lead to erroneous geophysical parameter estimates. It is thus necessary to accurately identify the samples that might be affected by rain. Following the experience of Topex/Poseidon [1], [2], the Envisat altimeter (RA2) operational rain flag is based on differential attenuation of the altimeter signals between the primary (Ku-band) and secondary (S-band) channels [4]. The rain flagging procedure involves testing whether measured backscatters $\left(\sigma_{0}\right)$ at $\mathrm{Ku}$ - and $\mathrm{S}$-bands lie outside predefined threshold relations. Currently, the $\mathrm{Ku} / \mathrm{S}$-band "rain-free" $\sigma_{0}$ relationship, used operationally, was estimated using only the first two months of data (November-December 2002) [4]. Some problems related to seasonal representativity of the relation (as already shown by Quartly et al. [5] for Topex) were detected in the flag, and an updated version has been computed over a one-year period (2003). The validation of the updated rain flag is presented hereafter.

The algorithm performances are assessed following the work of Tran et al. [6] who evaluated two Jason-1 altimeter rain flags via collocations with data from the Tropical Rainfall Measuring Mission (TRMM) Microwave Imager (TMI). The evaluation was conducted using dichotomous discrimination, i.e., in terms of percentage of hits, misses, false alarms (FAs), and correct negative $(\mathrm{CN})$ cases using the TMI data as references (see

Manuscript received April 4, 2008; revised May 16, 2008 and June 11, 2008. Current version published October 22, 2008. This work was supported by the European Space Agency (ESA).

N. Tran is with the Collecte Localisation Satellites (CLS), Space Oceanography Division, 31520 Ramonville St-Agne, France (e-mail: ntran @cls.fr).

J. Tournadre is with IFREMER, Technopole Brest-Iroise, 29280 Plouzané, France.

P. Féménias is with the European Space Research Institute for Earth Observation (ESRIN), European Space Agency, 00044 Frascati, Italy.

Digital Object Identifier 10.1109/LGRS.2008.2002043
TABLE I

YES-NO DISCRIMINATION DEFINITIONS

\begin{tabular}{lccc}
\hline \hline \multirow{2}{*}{ yes-no discrimination } & & \multicolumn{2}{c}{ TMI or PR rain flag } \\
\cline { 3 - 4 } & & Yes & No \\
\hline Envisat & Yes & Hits & False alarms (FA) \\
Rain flag & No & Misses & Correct negatives (CN) \\
\hline \hline
\end{tabular}

Table I). Limitation of such an approach is that TMI rain retrieval has its own uncertainties [7], [8]. However, TRMM also carries another rain sensor, i.e., the precipitation radar (PR) that can be used as a second and independent source of rain data to assess the RA2 rain flag. The PR measurement accuracy also depends on its own retrieval algorithm shortcomings. The comparison of TMI- and PR-derived rain rates (RRs) by Ikai and Nakamura [8] showed that in zonal average, PR underestimates the zonal mean RR by $\sim 24 \%$ over the tropical region.

The dual-collocation strategy (i.e., pairing RA2 data with TMI and PR data independently), used in this letter, allows that neither of these references is considered as the "sole truth" and helps to better qualify the Envisat performance with respect to either TMI or PR accuracy. The collocated data sets also provide a good opportunity to further validate the RRs inferred from dual-frequency altimeter data. Indeed, as recently shown by Tournadre [3], the joint use of the satellite microwave radiometer (MWR) and altimeter data allows the estimate of freezing level (FL) height and significantly improves the RR estimates. However, these RR estimates were validated only by statistical comparison of climatology.

\section{DATA SETS}

\section{A. Envisat Microwave Sensors}

The Envisat platform, launched in March 2002, carries ten different sensors. The satellite orbit is sun-synchronous at an altitude of $800 \mathrm{~km}$ with an inclination of $98.55^{\circ}$ with a 35-day repeat cycle and a three-day repeat subcycle. It carries a radar altimeter (RA2), derived from the ERS altimeters [10], and an MWR. RA2 is a dual-frequency radar that operates at $\mathrm{Ku}-$ band $(13.575 \mathrm{GHz})$ and at S-band $(3.2 \mathrm{GHz})$. The estimation of geophysical quantities is done on-ground by retracking the measured echo waveforms. The MWR is a dual-channel Dicketype radiometer operating at 23.8 and $36.5 \mathrm{GHz}$. A detailed description of the standard Geophysical Data Record product used in this study can be found in the Products handbook [11].

\section{B. TRMM Sensors}

The primary goal of the TRMM satellite, launched in November 1997, is to measure rainfall in the tropics. It carries five instruments, including the TMI and the PR. The TMI 
sensor is a multichannel dual-polarized MWR that utilizes nine channels operating at five frequencies between 10.7 and $85 \mathrm{GHz}$ at different polarizations. It provides data related to the rainfall rates over the oceans [7], [12]. The effective field of view depends on frequency (from $5 \times 7 \mathrm{~km}$ at $85 \mathrm{GHz}$ to $63 \times 37 \mathrm{~km}$ at $10.7 \mathrm{GHz}$ ), but rain data are delivered at cross-track intervals of about $5 \mathrm{~km}$ and along-track intervals of $14 \mathrm{~km}$ over a $759-\mathrm{km}$-width swath. The 2A12 TMI profiling product, version 6 used here, provides information on surface RR and rain/no-rain flag. A detailed description of the retrieval and rain product from TMI is given in [7]. The PR primary objective is to provide the 3-D structure of rainfall. It is a 128-element active phase array system operating at $\mathrm{Ku}$-band $(13.8 \mathrm{GHz})$. PR has a horizontal ground resolution of about $4 \mathrm{~km}$ and a swath width of $215 \mathrm{~km}$. It provides vertical profiles of the rain from the surface up to a height of about $20 \mathrm{~km}$. $\mathrm{PR}$ is able to separate out rain echoes for vertical sample sizes of about $250 \mathrm{~m}$ at nadir [12]. We used the version 6 standard 2A25 PR profile product that includes different RR estimates and associated quality flags [7].

\section{Collocated Data Selection}

The TMI and PR swath data are utilized here on a pixel basis. Data over land or with quality flag set were first discarded. The pairing of the Envisat and TRMM sensor (TMI or PR) data is done as follows. For each RA2 sample, the TRMM samples that match the time window (set to $10 \mathrm{~min}$ ) are selected, and then, among them, only those that match the distance criterion (set to $10 \mathrm{~km}$ ) are kept. Along the collocated pairs of the closest RA2/TRMM pairs, all the TRMM data within $100 \mathrm{~km}$ of the RA2 measurements are also selected to keep the environmental context necessary to analyze such a sporadic event as rainfall. The two collocation data sets span an 18-month period, i.e., from October 2002 to March 2004.

Although the number of collocated samples is quite large, only a few percentages of them are rainy. As rain is a highly sporadic and localized phenomenon, even a short time separation of $10 \mathrm{~min}$ is quite lenient in regard to the time and space scales of rain events, particularly for convective rain cells; however, strengthening the collocation criterion drastically reduces the number of collocated samples, and a compromise has to be found between the statistical and the physical significance of the analysis. This shows the difficulty of any validation of satellite-borne rain measurement and the care that should be taken when interpreting the results of statistical analysis. One method to overcome the problem is to consider not only the best collocated pairs but also their context. Indeed, even in relatively large temporal collocation cases where the advection of rain cells can become significant, it is possible using the context given by the wide swath of TMI and PR sensors to determine the presence (or absence) of rain in the vicinity of the RA2 samples.

\section{RAIN DETECTION}

\section{A. Algorithm Overview}

The Envisat rain flag is similar to the one defined for Topex by Tournadre and Morland [1]. It is set if the measured
$\mathrm{Ku}$-band $\sigma_{0}^{\mathrm{Ku}}$ is significantly attenuated when compared with the one that can be expected from the one measured at S-band, i.e.,

$$
\Delta \sigma_{0}=f\left(\sigma_{0}^{\mathrm{S}}\right)-\sigma_{0}^{\mathrm{Ku}}>A
$$

where $f$ is the mean $\mathrm{Ku} / \mathrm{S}$ "rain-free" relationship and $A$ is an attenuation threshold set to the minimum of 1.8 times the rms of $f$ and $0.5 \mathrm{~dB}$. The $f$ relation and its rms are estimated as binned averaged and rms of $\sigma_{0}^{\mathrm{Ku}}$ with respect to $\sigma_{0}^{\mathrm{S}}$ by step of $0.1 \mathrm{~dB}$. They were recomputed from 2003 year-period data, and they will be used in the reprocessing of the Envisat altimeter mission starting in late 2008. To reduce the probability of FA, the presence of liquid water within the atmosphere is ensured by testing that the MWR cloud liquid water content is greater than a threshold fixed here at $0.2 \mathrm{~kg} \cdot \mathrm{m}^{-2}$. Because of the altimeter design and performances and because of the natural geophysical and instrumental variability of $\mathrm{Ku}$-band $\sigma_{0}$, only attenuation larger than $\sim 0.25 \mathrm{~dB}$ is detectable by the algorithm which corresponds to a rainfall rate of about $1 \mathrm{~mm} \cdot \mathrm{h}^{-1}$ for a 4-km rain height [3].

\section{B. Validation}

The performances of the RA2 rain flag are assessed by comparison with the TRMM rain data following the method presented by Tran et al. [6] for Jason-1. The relative performances of the detection are evaluated using the dichotomous discrimination (see Table I) for different collocation criteria. Because RA2 and the TRMM sensors have different sensitivities to rain and as the RA2 lower limit of detection is about $1 \mathrm{~mm} \cdot \mathrm{h}^{-1}$, only $\mathrm{RR}$ larger than this limit is considered as rainy for the TRMM instruments in the dichotomous discrimination. Table II presents the comparison of rain detection by TRMM sensors (TMI and PR) $\left(\mathrm{RR}>1 \mathrm{~mm} \cdot \mathrm{h}^{-1}\right)$ and the new version of RA2 flag at different collocation criteria.

TMI-Envisat Comparison: Because of the TMI and RA2 difference of resolution ( $\sim 25 \mathrm{~km}$ versus $8 \mathrm{~km}$ ), each TMI sample is, in general, associated with two RA2 samples in the database. For a pertinent comparison, the RA2 samples associated to the same TMI sample are thus averaged to produce an average sample whose rain flag is set if one of the individual ones is set and whose RR is the mean RR. The number of collocated samples decreases sharply when the separation in time decreases and the tightest criteria $(1 \mathrm{~min}, 5 \mathrm{~km})$ are met by only 5755 samples. However, the influence of the collocation criteria is quite limited. The proportion of samples detected as rainy (hits and FA) by RA2 is $\sim 2.9 \%$, whereas it is only $\sim 1.7 \%$ for TMI (hits and misses). This proportion for TMI rises to $2.6 \%$ (3.3\%) if RR greater than $0.5 \mathrm{~mm} \cdot \mathrm{h}^{-1}$ $\left(0.3 \mathrm{~mm} \cdot \mathrm{h}^{-1}\right)$ is considered. RA2 detects thus about the same number of samples as TMI at a $0.3-\mathrm{mm} \cdot \mathrm{h}^{-1}$ level which is compatible with the difference of resolution of the two sensors. The percentage of misses is quite low at $\sim 0.4 \%$, and it is almost independent of the collocation criteria. Within this percentage, $\sim 0.38 \%$ corresponds to situations where either the RA2 $\mathrm{Ku}$-band $\sigma_{0}$ is significantly attenuated $\left(\Delta \sigma_{0}>0.1 \mathrm{~dB}\right)$ but not largely enough to trigger the rain flag, or situations of low TMI RR $\left(<1.5 \mathrm{~mm} \cdot \mathrm{h}^{-1}\right)$. Such cases can be considered as dubious misses and can be related to the natural variability of rain. The proportion of "real misses" is thus about $0.02 \%$ 
TABLE II

Dichotomous Discrimination (IN PERCENT) BETWEen TRMM (TMI AND PR) AND RA2 FOR DifFERENT COLLOCATION CRITERIA. THE NuMBERS IN Parentheses in the Misses and FA Categories Represent the Numbers of Dubious Samples (See Text). CN: Correct Negative

\begin{tabular}{|c|c|c|c|c|c|c|c|c|c|c|}
\hline $\begin{array}{l}\text { TRMM Sensor } \\
\text { Collocation } \\
\text { criterion }\end{array}$ & \multicolumn{5}{|c|}{ TMI } & \multicolumn{5}{|c|}{ PR } \\
\hline $10 \mathrm{~min}, 5 \mathrm{~km}$ & 59004 & $0.41(0.38)$ & 1.22 & 96.73 & $1.63(1.48)$ & 50007 & $0.16(0.15)$ & 0.73 & 97.79 & $1.32(1.24)$ \\
\hline $5 \mathrm{~min}, 5 \mathrm{~km}$ & 29433 & $0.39(0.38)$ & 1.29 & 96.60 & $1.72(1.57)$ & 25428 & $0.13(0.11)$ & 0.79 & 97.80 & $1.27(1.22)$ \\
\hline $1 \mathrm{~min}, 5 \mathrm{~km}$ & 5755 & $0.43(0.43)$ & 1.16 & 96.61 & $1.80(1.77)$ & 5118 & $0.20(0.17)$ & 0.98 & 97.61 & $1.21(1.17)$ \\
\hline
\end{tabular}

and represents less than $1 \%$ of the TMI rainy samples. It is even zero for the best collocation criteria $(1 \mathrm{~min}, 5 \mathrm{~km})$. The proportions of hits and $\mathrm{CN}$ are almost constant at about $1.2 \%$ and $96.7 \%$, respectively. The percentage of FA is quite high at $\sim 1.7 \%$. These FA cases have been carefully screened, and the contextual information has been used to test the presence of rain in the vicinity of the TMI nonrainy samples as well as the intensity and size of the RA2 rain events. This analysis reveals that $\sim 1.5 \%$ of the FA is associated with one or more of the following situations: 1) TMI RR is larger than 0 but smaller than $1 \mathrm{~mm} \cdot \mathrm{h}^{-1} ; 2$ ) one of the paired RA2 samples associated to a TMI sample is rainy, whereas the other is nonrainy; 3 ) the Envisat liquid water content is less than $0.5 \mathrm{~kg} \cdot \mathrm{m}^{-2}$, indicating rain cells of small dimension; and 4) one of the neighboring TMI samples is rainy. These cases correspond thus to either small or light rain cells undetected by the larger resolution TMI sensor, or they are related to a significant time/space variation of rain. The "real FA" proportion is thus quite low at $\sim 0.1 \%-0.2 \%$. It is even as low as $0.03 \%$ for the best collocation criteria. This represents between $2 \%$ and $10 \%$ of the TMI rain cases. Considering the natural rain variability, the performance of the RA2 rain flag is better than $99 \%$ in detection with a proportion of FA about $5 \%-10 \%$ when compared with the TMI rain detection. The analysis thus shows that the RA2 rain detection performs at least as well as the TMI rain algorithm with a very low rate of misses and a reasonable FA rate lower than $10 \%$.

PR-Envisat Comparison: The proportion of rainy samples is $\sim 2 \%$ for RA2 and $\sim 1 \%$ for PR at a $1-\mathrm{mm} \cdot \mathrm{h}^{-1}$ threshold. The PR proportion rises to $1.6 \%$ at a $0.25-\mathrm{mm} \cdot \mathrm{h}^{-1}$ level. The proportion of misses is lower than that of TMI and is less than $0.2 \%$. Within these missed PR rainy samples, $\sim 0.16 \%$ are associated with either an RA2 Ku-band $\sigma_{0}$ significantly attenuated $\left(\Delta \sigma_{0}>0.1 \mathrm{~dB}\right)$ but not largely enough to trigger the rain flag, or by at least one RA2 neighboring sample (within $20 \mathrm{~km}$ ) flagged as rainy. The percentage of "real misses" is thus $\sim 0.02 \%-0.03 \%$, i.e., $\sim 1 \%$ of the RA2-flagged samples. The proportions of hits and $\mathrm{CN}$ are almost independent of the collocation criteria at about $0.7 \%$ and $97.8 \%$, respectively. The percentage of FA is lower than that of TMI but still quite high at $\sim 1.3 \%$. As for TMI, a careful analysis of the contextual environment of the samples shows that about $1.2 \%$ correspond to situations where either one of the neighboring PR samples (within $20 \mathrm{~km}$ ) is rainy or where the RA2 neighboring samples are nonrainy. Thus, about $0.1 \%$ of the data can be considered as "real misses," which represent $\sim 10 \%$ of the PR rainy samples.
The PR and RA2, which have comparable resolution, show similar rain detection statistics.

The comparison of the RA2 rain detection flag with both TMI and PR shows that its performances are comparable to the rain retrieval algorithm of these two instruments.

\section{RR Estimates}

\section{A. Algorithm Overview}

A detailed description of the method for estimating FLs and RRs from dual-frequency altimeter and MWR is given in [3] and is only very briefly summarized hereafter. For all samples detected as rainy, the FL is inferred by the inversion of the microwave (MWR) brightness temperatures in an approach similar to the one developed for SSM/I by Wilheit et al. [13]. The RR is then computed from the FL (or H) and attenuation using the Marshal-Palmer relation [14]

$$
\mathrm{RR}=\left(\Delta \sigma_{0} / 2 H a\right)^{1 / b}
$$

where $a$ and $b$ are frequency-dependent coefficients and whose values are $a=0.0238 \mathrm{~dB} \cdot \mathrm{km}^{-1}$ and $b=1.203$ [5]. Comparison of Topex, Jason-1, and Envisat dual-frequency RR estimates by Tournadre [3] showed that Envisat overestimated low RRs. Using a histogram-matching technique, he proposed an intercalibration relation with Jason-1 RR estimates that significantly reduces the differences between the mean annual RR computed from Envisat and those from both Topex and Jason-1 missions.

\section{B. Validation}

The quality of the RA2 rain estimates is assessed here through direct comparison with independent estimates from two sensors with different resolution and technology. The mean difference and standard deviation (std) for the TRMM sensors (TMI and PR) and RA2 collocated RR estimates for different collocation criterions are presented in Table III. Two RA2 RRs are considered: the raw estimates computed with (2) and the raw estimates corrected using the calibration relationship proposed by Tournadre [3]. For the TMI comparison, the mean RR of the two RA2 samples collocated with the same TMI sample is considered to take into account the difference in resolution. Fig. 1 shows the comparison of TMI and RA2 RR estimates. The scatter plots [Fig. 1(a) and (b)] show that, although the data set covers 18 months, very few RRs larger than $10 \mathrm{~mm} \cdot \mathrm{h}^{-1}$ 

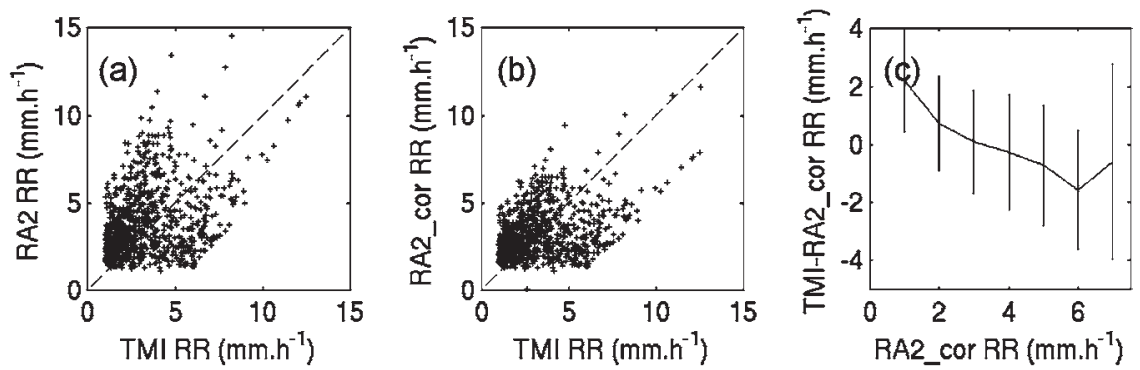

Fig. 1. Comparison of TMI RR estimates (a) with RA2 raw and (b) calibrated estimates. (c) Mean difference between TMI and RA2 calibrated estimates as a function of RA2 rain estimates. The error bars represent the std magnitudes.

TABLE III

Mean Difference and STD in Millimeters Per Hour Between the TMI (or PR) and RA2 RR Raw and Corrected Values

\begin{tabular}{|c|c|c|c|c|c|c|c|c|c|c|c|c|c|c|c|c|c|c|}
\hline \multirow{3}{*}{$\begin{array}{l}\text { TRMM Sensor } \\
\begin{array}{l}\text { Collocation } \\
\text { criterion }\end{array}\end{array}$} & \multicolumn{5}{|c|}{ TMI surface rain rate } & \multicolumn{5}{|c|}{ PR AR1 } & \multicolumn{4}{|c|}{ PR AR2 } & \multicolumn{4}{|c|}{ PR ESR } \\
\hline & \multirow[t]{2}{*}{$N$} & \multicolumn{2}{|c|}{ RA2 raw } & \multicolumn{2}{|c|}{ RA2 corr. } & \multirow{2}{*}{$\mathrm{N}$} & \multicolumn{2}{|c|}{ RA2 raw } & \multicolumn{2}{|c|}{ RA2 corr. } & \multicolumn{2}{|c|}{ RA2 raw } & \multicolumn{2}{|c|}{ RA2 corr. } & \multicolumn{2}{|c|}{ RA2 raw } & \multicolumn{2}{|c|}{ RA2 corr. } \\
\hline & & mean & std & mean & std & & mean & std & mean & std & mean & std & mean & std & mean & std & mean & std \\
\hline $10 \mathrm{~min}, 10 \mathrm{~km}$ & 833 & -0.52 & 2.30 & 0.14 & 2.00 & 334 & -1.42 & 2.06 & -0.44 & 1.78 & -2.65 & 2.05 & -1.55 & 1.55 & -0.91 & 2.07 & -0.06 & 1.81 \\
\hline $10 \mathrm{~min}, 5 \mathrm{~km}$ & 655 & -0.49 & 2.33 & 0.16 & 2.04 & 330 & -1.41 & 2.04 & -0.42 & 1.77 & -2.63 & 2.05 & -1.56 & 1.55 & -0.90 & 2.05 & -0.04 & 1.84 \\
\hline $5 \mathrm{~min}, 5 \mathrm{~km}$ & 350 & -0.49 & 2.40 & 0.19 & 2.07 & 186 & -1.40 & 2.06 & -0.38 & 1.79 & -2.85 & 1.87 & -1.73 & 1.31 & -1.04 & 2.07 & -0.13 & 1.82 \\
\hline $5 \mathrm{~min}, 2.5 \mathrm{~km}$ & 158 & -0.36 & 2.49 & 0.32 & 2.16 & 100 & -1.51 & 2.05 & -0.45 & 1.79 & -2.93 & 1.79 & -1.80 & 1.26 & -1.26 & 1.97 & -0.35 & 1.72 \\
\hline $1 \mathrm{~min}, 5 \mathrm{~km}$ & 64 & -0.65 & 1.91 & -0.07 & 1.80 & 48 & -1.06 & 1.86 & -0.24 & 1.58 & -2.37 & 1.38 & -1.54 & 1.01 & -1.00 & 2.07 & -0.12 & 1.86 \\
\hline
\end{tabular}

are detected, showing the difficulty of validating high RRs. The dispersion between the TMI and RA2 RR is quite large for raw RA2 RR and is significantly reduced for the corrected ones. The mean bias (TMI-RA2), i.e., $\sim 0.5 \mathrm{~mm} \cdot \mathrm{h}^{-1}$ with an std of $\sim 2.3 \mathrm{~mm} \cdot \mathrm{h}^{-1}$ for the raw RR, reduces to $0.14 \mathrm{~mm} \cdot \mathrm{h}^{-1}$ with an std of $2 \mathrm{~mm} \cdot \mathrm{h}^{-1}$ for the corrected values. Both bias and std vary only marginally when the collocation criterion is restricted. Fig. 1(c), which presents the TMI/RA2 mean difference as a function of RA2 RR, shows that the corrected RA2 RR underestimates low rain $\left(<4 \mathrm{~mm} \cdot \mathrm{h}^{-1}\right)$, overestimates the ones between 4 and $6 \mathrm{~mm} \cdot \mathrm{h}^{-1}$, and certainly underestimates the higher ones.

Attenuation measured by an altimeter corresponds to the integrated attenuation between the rain bottom and the rain top. Rainfall inferred from attenuation using (2) corresponds thus to an RR averaged between the surface and the FL. Several RRs can be estimated from the PR vertical profile of rain and are available in the $2 \mathrm{~A} 25$ products: the estimated surface rain (PR_ESR), i.e., the rainfall estimate at the detected surface bin, the average RR (PR_AR1) between the two predefined levels of 2 and $4 \mathrm{~km}$, and the mean RR from rain top to rain bottom (PR_AR2). PR_AR2 definition is thus the most similar to the RA2 one. These PR rainfall estimates were compared with both RA2 raw and calibrated RR (see Table III and Fig. 2). The comparison shows that the raw RA2 RR largely overestimates the PR ones: by $1.42 \mathrm{~mm} \cdot \mathrm{h}^{-1}$ for PR_AR1, $2.65 \mathrm{~mm} \cdot \mathrm{h}^{-1}$ for PR_AR2, and $0.91 \mathrm{~mm} \cdot \mathrm{h}^{-1}$ for PR_ESR. The stds are however quite similar at $\sim 2 \mathrm{~mm} \cdot \mathrm{h}^{-1}$, and the impact of the collocation criterion on the bias and the std is limited. The best collocation criterion gives better results for PR_AR1 and PR_AR2, but the number of samples (48) is far too limited for a good statistical confidence of the result. The calibration of RA2 RR significantly reduces the biases with the three PR estimates by nearly $1 \mathrm{~mm} \cdot \mathrm{h}^{-1}$ and the std by
$10 \%-20 \%$. The bias is minimum with PR_ESR and maximum with PR_AR2, whereas the std is maximum with PR_ESR and minimum with PR_AR2. The mean difference between the PR and RA2 estimates shown in Fig. 2(g)-(i) shows that RA2 RR estimate is in better agreement with PR_ESR as the bias to this rain estimate is only weakly dependent on rain intensity. This is not the case for the two other PR RRs for which the bias strongly increases with rain intensity to reach $4 \mathrm{~mm} \cdot \mathrm{h}^{-1}$ at $8 \mathrm{~mm} \cdot \mathrm{h}^{-1}$ for PR_AR2. This comparison analysis shows that the RA2 RR compares very well to PR_ESR. The bias and the std between the RA2 and the averaged PR estimates are quite similar to the ones computed for the same samples between the PR_ESR and these two quantities, i.e., mean bias of $-0.30 \mathrm{~mm} \cdot \mathrm{h}^{-1}\left(-1.9 \mathrm{~mm} \cdot \mathrm{h}^{-1}\right)$ with an std of $1.91 \mathrm{~mm}$. $\mathrm{h}^{-1}\left(1.7 \mathrm{~mm} \cdot \mathrm{h}^{-1}\right)$ for PR_AR1 (PR_AR2). The scatter plots and the mean biases as a function of RR between the PR_ESR and the PR averaged RRs (not shown here) confirm that RA2 RRs behave like the PR_ESR.

\section{CONCLUSiON}

One year of Envisat RA2 data from 2003 has been used to estimate the updated rain-free relations necessary to accurately flag rain-affected data, while 18 months of them have been used to evaluate the performances of this new version of Envisat algorithm from collocated data sets with TMI and PR, respectively. The results of the validation show that the rain flag has overall good performances. The score of detection is about 99\%, whereas the FA rate is lower than 10\% compared with TMI and PR. The percentage of RA2-flagged samples is quite stable with time at $\sim 3 \%$ per 35 -day cycle.

The study has also shown that the RA2 rain products are very complementary to the PR and TMI ones. Envisat can provide an independent estimate of FL altitude with a precision as good as 

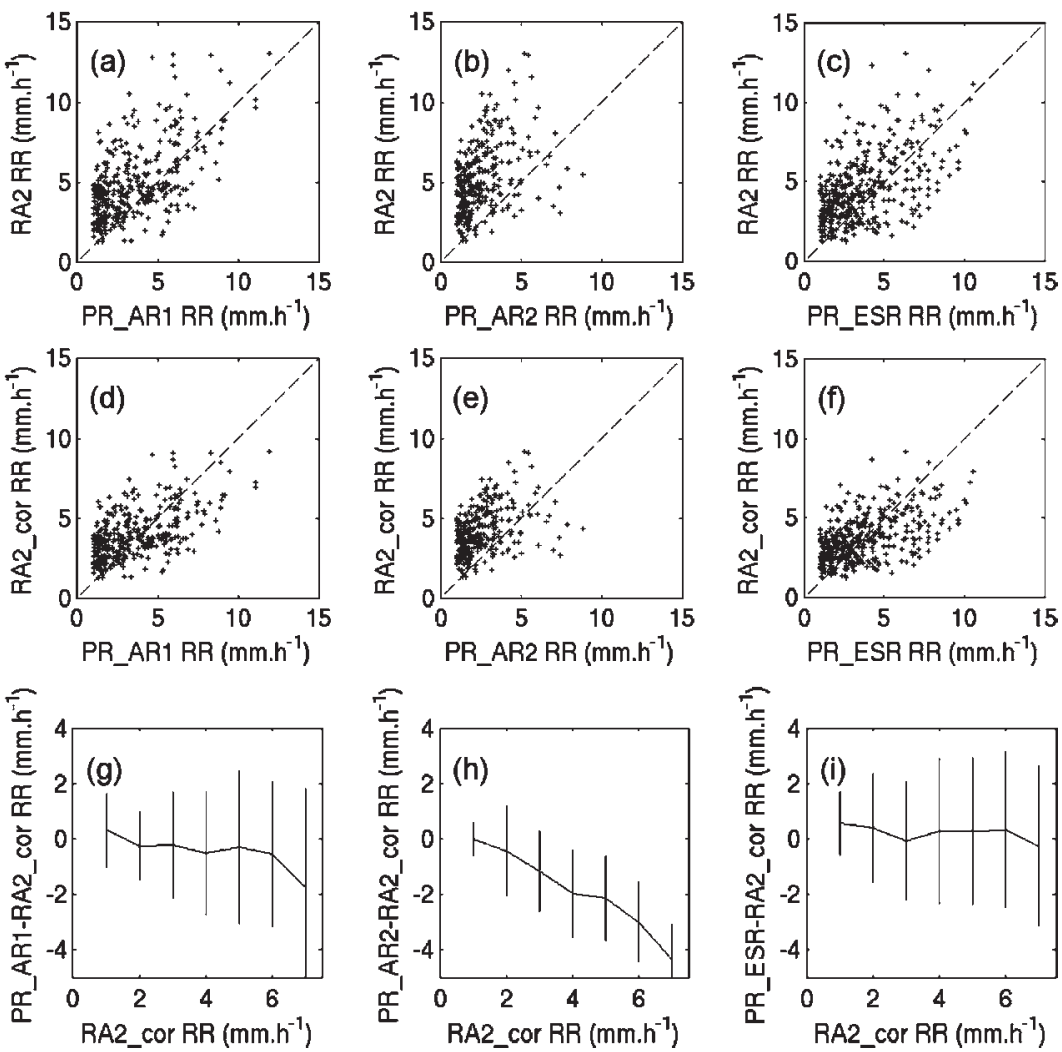

Fig. 2. Same as Fig. 1 but with PR RR estimates. (a), (d), and (g) PR rain average from 2 to 4 km, PR_AR1. (b), (e), and (h) PR RR average from rain top to rain bottom, PR_AR2. (c), (f), and (i) PR estimated surface RR, PR_ESR.

or even better than the SSM/I one [3]. RR estimates, particularly when corrected using the calibration relation of Tournadre [3], are comparable to the PR estimated surface RR with a small bias of $-0.1 \mathrm{~mm} \cdot \mathrm{h}^{-1}$ and a $1.8-\mathrm{mm} \cdot \mathrm{h}^{-1} \mathrm{std}$. The comparison to TMI shows that TMI RRs have a small positive bias of $\sim 0.2 \mathrm{~mm} \cdot \mathrm{h}^{-1}$ and an std of $\sim 2 \mathrm{~mm} \cdot \mathrm{h}^{-1}$. TMI RRs are thus larger than the RA2 ones themselves larger than the PR ones. This is in agreement with the comparison of TMI and PR RRs conducted by Ikai and Nakamura [8] which showed a general overestimation of rain by TMI. The analysis shows that the RA2 rain estimates can certainly be used as an independent data set complementary to the ones used in the Global Precipitation Climatology Project for climatological studies and can be of interest for precipitation climatology at midlatitude where no data from TRMM are available.

\section{ACKNOWLEDGMENT}

The authors would like to thank the Goddard Space Flight Center Distributed Active Archive Center for the straightforward and rapid access via ftp to the TRMM data. The authors would also like to thank the reviewers for their helpful comments.

\section{REFERENCES}

[1] J. Tournadre and J. C. Morland, "The effects of rain on TOPEX/ POSEIDON altimeter data," IEEE Trans. Geosci. Remote Sens., vol. 35, no. 5, pp. 1117-1135, Sep. 1997.

[2] G. D. Quartly, T. H. Guymer, and M. A. Srokosz, "The effects of rain on TOPEX radar altimeter data," J. Atmos. Ocean. Technol., vol. 13, no. 6, pp. 1209-1229, Dec. 1996.
[3] J. Tournadre, "Improved level-3 oceanic rainfall retrieval from dualfrequency spaceborne radar altimeter systems," J. Atmos. Ocean. Technol., vol. 23, no. 8, pp. 1131-1149, Aug. 2006.

[4] J. Tournadre, "Validation of Jason and Envisat altimeter dual frequency rain flags," Mar. Geod., vol. 27, no. 1/2, pp. 153-169, 2004.

[5] G. D. Quartly, M. A. Srokosz, and T. H. Guymer, "Global precipitation statistics from dual-frequency TOPEX altimetry," J. Geophys. Res., vol. 104, no. D24, pp. 31489-31516, 1999.

[6] N. Tran, E. Obligis, and F. Ferreira, "Comparison of two Jason-1 altimeter precipitation detection algorithms with rain estimates from the TRMM microwave imager," J. Atmos. Ocean. Technol., vol. 22, no. 6, pp. 782794, Jun. 2005.

[7] C. Kummerow et al., "The evolution of the Goddard Profiling Algorithm (GPROF) for rainfall estimation from passive microwave sensors," J. Appl. Meteorol., vol. 40, no. 11, pp. 1801-1820, Nov. 2001

[8] J. Ikai and K. Nakamura, "Comparison of rain rates over the ocean derived from TRMM microwave imager and precipitation radar," J. Atmos. Ocean. Technol., vol. 20, no. 12, pp. 1709-1726, Dec. 2003.

[9] C. D. Kummerow et al., "The status of the tropical rainfall measuring mission (TRMM) after two years in orbit," J. Appl. Meteorol., vol. 39, no. 12, pp. 1965-1982, Dec. 2000.

[10] J. Benveniste, M. Roca, P. Vincent, G. Levrini, S. Baker, O.-Z. Zanife, and C. Zelli, "The Envisat radar altimetry mission: RA-2, MWR, DORIS and LRR," ESA Bull., vol. 105, pp. 67-76, 2001.

[11] J. Benveniste, S. Baker, O. Bombaci, C. Zeli, P. Venditti, O.-Z. Zanife, B. Soussi, J.-P. Dumont, J. Stum, and M. P. Milagro-Perez, Envisat RA-2/ MWR Product Handbook. Paris, France: ESA, 2002. PO-TN-ESR-RA0050. [Online]. Available: http://envisat.esa.int/

[12] C. D. Kummerow, W. Barnes, T. Kozu, J. Shiue, and J. Simpson, "The tropical rainfall measuring mission (TRMM) sensor package," J. Atmos. Ocean. Technol., vol. 15, no. 3, pp. 809-817, Jun. 1998.

[13] T. T. Wilheit, A. T. C. Chang, and L. S. Chiu, "Retrieval of monthly rainfall indices from microwave radiometric measurements using probability distribution functions," J. Atmos. Ocean. Technol., vol. 8, no. 1, pp. 118136, Feb. 1991.

[14] J. Marshall and W. M. Palmer, "The distribution of raindrops with size," J. Meteorol., vol. 5, no. 4, pp. 165-166, Aug. 1948. 